University of Nebraska - Lincoln

DigitalCommons@University of Nebraska - Lincoln

Faculty Publications: Department of Entomology

Entomology, Department of

March 2007

\title{
Maggot Development during Morgue Storage and Its Effect on Estimating the Post-Mortem Interval
}

Timothy Huntington

University of Nebraska-Lincoln

Leon G. Higley

University of Nebraska-Lincoln, Ihigley1@unl.edu

Frederick P. Baxendale

University of Nebraska-Lincoln, fbaxendale1@unl.edu

Follow this and additional works at: https://digitalcommons.unl.edu/entomologyfacpub

Part of the Entomology Commons

Huntington, Timothy; Higley, Leon G.; and Baxendale, Frederick P., "Maggot Development during Morgue Storage and Its Effect on Estimating the Post-Mortem Interval" (2007). Faculty Publications: Department of Entomology. 131.

https://digitalcommons.unl.edu/entomologyfacpub/131

This Article is brought to you for free and open access by the Entomology, Department of at DigitalCommons@University of Nebraska - Lincoln. It has been accepted for inclusion in Faculty Publications: Department of Entomology by an authorized administrator of DigitalCommons@University of Nebraska - Lincoln. 
Published in Journal of Forensic Sciences 52:2 (March 2007), pp. 453-458; doi 10.1111/j.1556-4029.2007.00385.x

Copyright (c) 2007 by American Academy of Forensic Sciences; published by Blackwell Publishing. Used by permission.

http://www.blackwell-synergy.com

Presented at the 2006 Annual Meeting of the American Academy of Forensic Sciences, Seattle, WA, February 24, 2006.

\title{
Maggot Development during Morgue Storage and Its Effect on Estimating the Post-Mortem Interval
}

\author{
Timothy E. Huntington, M.S., Leon G. Higley, Ph.D., and Frederick P. Baxendale, Ph.D. \\ Department of Entomology, University of Nebraska, 202 Plant Industry Building, Lincoln, NE 68583. \\ Correspondence: Timothy E. Huntington, email: timh@unlserve.unl.edu
}

\begin{abstract}
When insect evidence is obtained during autopsy, forensic entomologists make decisions regarding the effects of low-temperature $\left(-1^{\circ} \mathrm{C}\right.$ to $\left.4^{\circ} \mathrm{C}\right)$ storage of the body and associated insects when estimating the post-mortem interval (PMI). To determine the effects of storage in a morgue cooler on the temperature of maggot masses, temperatures inside and outside of body bags containing a human cadaver and porcine cadavers (seven replicates) were measured during storage. Temperatures remained significantly higher $(p<0.05)$ inside of the body bags relative to the cooler, and remained at levels sufficient for maggot feeding and development. If the assumption that no insect development takes place during preautopsy refrigeration is made, potential error rates in PMI estimation of 8.6-12.8\% occur. The potential for blow fly larvae to undergo significant development while being stored in the morgue is a possibility that forensic entomologists should consider during an investigation involving samples collected from autopsy. Case and experimental evidence also demonstrate that substantial tissue loss can occur from maggot feeding during morgue storage.
\end{abstract}

Keywords: forensic science, forensic entomology, Calliphoridae, insect development, autopsy, maggot mass temperature

During the course of an investigation involving insects and human remains, insect evidence is frequently not collected from the corpse until autopsy. In the time between removal from the recovery scene and autopsy, the remains are typically stored in a cooler or refrigeration unit with temperatures ranging from $-1^{\circ} \mathrm{C}$ to $4^{\circ} \mathrm{C}$. The duration of time that the remains are in the cooler may range from a few hours to several days (1).

At the time of autopsy, insect evidence can readily be collected in most cases, and the procedures to do so are outlined in several publications (2-4). An important consideration when analyzing evidence collected at autopsy is the length of time that the insects were in the cooler, the temperatures the insects experienced in the cooler, and the effect, if any, of cooler temperatures on maggot development. The first of these questions is easily answered by checking with the staff at the morgue as to when the body was received and when it was removed from the cooler. The other two questions are far more difficult to answer.

Determining the temperatures that insects experience while in the cooler is difficult because maggots often aggregate into maggot masses. A maggot mass is an assemblage of feeding larvae in which metabolic heat increases the microclimate temperature above ambient (5). This behavior and its influence on temperature have been known since 1869 (6). Entomologists now recognize that an increase in temperature normally occurs when large groups of maggots are feeding $(7,8)$.

A debate exists as to whether or not refrigeration has an effect on maggot development. Many authors maintain that maggot mass temperatures will be maintained under refrigerated conditions $(2-4,9,10)$, but the claim has been made that refrigeration of a body lowers maggot mass temperatures sufficiently to cease maggot development (11).

During the course of a 2003 homicide investigation, we were able to track the temperatures experienced by the insects as- sociated with the victim from the time the body was removed from the scene until the autopsy. During the intervening time, the body was kept in a standard morgue cooler and the temperatures that were recorded showed that the insects were able to maintain high enough temperatures to be able to continue development despite the cold storage temperature. While this was not an unexpected result, this was possibly the first time that data of this nature were available to researchers and investigators. Consequently, we conducted subsequent experiments with decomposing pigs to confirm our observations on maggot development in a morgue cooler and to establish the magnitude of temperature differences. The aim of the current study was to determine whether maggot development in coolers is sufficient to bias post-mortem interval (PMI) estimates.

\section{Case Study}

The partially decomposed remains of a 50-year-old Caucasian male were discovered at about 08:20 hours, September 13, 2003, in the ditch of a rural Seward County, Nebraska, road. The remains were partially covered with dead tree limbs and were lying among tall roadside weeds. The victim was supine, with the left arm extended toward the head, elbow bent, and the right arm extended laterally away from the torso. The remains were clothed in underwear, and a t-shirt and belt bound the ankles. The body was in the "active decay" stage of decomposition (12), with extensive skeletonization of the head and partial skeletonization and mummification of the left hand. Skin slippage was noted on the legs and right hand. Significant maggot activity was noted in the head and neck, back, and upper extremities. Stab wounds (identified at autopsy) were located in the upper torso. Heavy insect activity was noted in these wounds. 
Temperatures and insects were collected from the victim and from the scene by the authors from 15:00 to 17:00 hours on September 13. When the body was removed from the scene by law enforcement officials, an Onset Hobo H8 data logger (Onset Computer Corporation, Pocasset, MA) was placed in a plastic bag and placed on top of the body, under the sheet that was used to wrap the body and inside of the body bag. The body bag was a medium-weight, black adult-sized transport bag. An additional Onset Hobo H8 data logger was placed in a plastic bag and attached to the outside of the body bag using duct tape. Both of these data loggers were recovered at autopsy on September 16, 2003, and the data were transferred to a computer via an Onset Hobo Shuttle (Onset Computer Corporation). The body was stored in a walk-in morgue cooler (unknown make) at $3.5^{\circ} \mathrm{C}$ for $\mathrm{c} .40 \mathrm{~h}$ before autopsy. In the case study presented here, the PMI was estimated to be 8.5 days, placing the time of death between sunset on September 4 and sunrise on September 5, 2003. This PMI was estimated through entomological analysis of Cochliomyia macellaria, a fly that typically delays oviposition (13), and was confirmed through suspect confessions and other independent evidence by the Lincoln Police Department, Lincoln, NE.

\section{Material and Methods}

Pig (Sus scrofa L.) cadavers were used as human analogs. These were procured from the Veterinary Diagnostic Center in Lincoln, NE, and the University of Nebraska Agricultural Research and Developmental Center Swine Unit near Mead, NE. Pigs received from the Veterinary Diagnostic Center died of natural causes, while pigs received from the ARDC Swine Unit had either been culled from production units or had been sacrificed because of injury. These pigs were killed by penetrating captive bolt to the brain. All pigs were disease-free, and received from each facility after they were already dead, which exempts this research from the University of Nebraska Institutional Animal Care and Use Program guidelines regarding living vertebrate animals that are used for research purposes (14).

Four pig cadavers were obtained from the Veterinary Diagnostic Clinic on October 12, 2004. These pigs had been necropsied, with internal abdominal and thoracic organs removed, enclosed in plastic garbage bags, and had been refrigerated at $4^{\circ} \mathrm{C}$ for $c .1 \mathrm{~h}$ before being picked up. Each cadaver weighed $c .11 \mathrm{~kg}$. These pigs were designated as "little pig" (LP) 1-4 for reference purposes. These pigs remained in the plastic garbage bags during transport to the study site.

Four pig cadavers were obtained from the ARDC Swine Unit on October 15, 2004. Each pig was contained in a clear plastic bag that was sealed at the ends. These pigs were designated as "big pig" (BP) 1-4 for reference purposes. BP1 was received fresh, while BP2-BP4 had been refrigerated for fewer than 3 days before being picked up. These pigs remained sealed in their bags during transport to the Veterinary Diagnostic Center, where they were weighed, and during transport to the study site. The weights of these pigs were $59,41,27$, and $25 \mathrm{~kg}$, respectively.

Refrigeration of pig cadavers has been shown to have no significant effect on the colonization of remains by insects, and insect development is unaffected. Frozen cadavers will decompose more rapidly than fresh cadavers due to increased aerobic metabolism (15), but insect activity is largely unchanged $(16,17)$.

Both groups of pigs (LP and BP) were placed at the study site for exposure to insects on the date that they were obtained. The study site was located on the University of Nebraska-Lincoln East Campus in an area of riparian woodland associated with a small creek. The predominant vegetation in the area includes Siberian elm (Ulmus pumila), white ash (Fraxinus americana), mulberry (Morus spp.), and smooth brome (Bromus inermis). The areas where the pigs were placed received occasional scattered sunlight during the day.

The LP cohort was placed at the study site at 10:00 hours on October 12, 2004. Pigs were placed on the ground, side by side (spaced c. $10 \mathrm{~cm}$ apart), with the right side up and heads pointing east. A sheet of hardware cloth (0.5 in. diameter) was placed over the pigs and was staked to the ground to prevent scavenging by vertebrates.

The BP cohort was placed at the study site at 14:15 hours on October 15, 2004. This group was placed on the ground c. $3 \mathrm{~m}$ from the LP group. Pigs were placed side by side (spaced $c$. $10 \mathrm{~cm}$ apart), and each pig was positioned with its right side up and head toward the north. To create additional sites for fly oviposition, each pig was stabbed one time in the right side of the neck with a hunting knife. A sheet of hardware cloth (0.5 in. diameter) was used to prevent scavenging by vertebrates as described above.

Pigs were checked daily for the presence and numbers of blow fly larvae. Experiments were initiated when maggots reached the premigratory third stage and were feeding in one or more maggot masses, which took place after c. 14 days. At this time, the hardware cloth cover was removed, and samples of the maggots were collected for identification. Half of the samples were fixed in boiling water and then preserved in $80 \%$ ethanol, while the other half was placed on raw beef liver and reared to adulthood in an environmental chamber set at $22^{\circ} \mathrm{C}$. These flies were identified to species level using diagnostic keys $(18,19)$.

After the insects were collected, each pig was placed on a clean white bed sheet ( $50 \%$ cotton $/ 50 \%$ polyester) and placed in a black, adult-size envelope-style body bag (Centennial Products Intl., Jacksonville, FL). Onset Hobo H8 Outdoor Industrial Loggers (Onset Computer Corporation) were used to record temperatures inside and outside of the body bags, with each of four thermocouples placed in the following four areas: the primary maggot mass on the pig, under the pig, on top of the pig, and outside of the body bag. The data logger itself was attached to the outside of the body bag with duct tape. The primary maggot masses were located in the thoracic cavity of each of the LP replicates, and in the mouths of the BP cohort. Temperatures were recorded at 10-min intervals. Transportation of the pigs from the study site to the morgue cooler took $<2 \mathrm{~min}$.

The LP group was transferred from the study site and placed in the morgue cooler on October 26, 2004 at 12:00 hours, and were removed from the cooler at 15:00 hours on October 28.

The BP cohort was transferred from the study site to the morgue cooler at 12:30 hours on November 2, 2004. This group of pigs was removed from the cooler at 09:00 hours on November 4 .

The morgue cooler used for the experiments was a walkin-type cooler with a Russell refrigeration unit (Russell, Brea, CA) that was located in the Veterinary Diagnostic Center on the University of Nebraska-Lincoln East Campus. This cooler is used primarily for the storage of dead animals and other specimens, and is similar to most walk-in coolers used to store human cadavers. The temperature is maintained at a constant $4^{\circ} \mathrm{C}$. Pigs from the LP group were placed on wire shelves within the cooler, whereas pigs from the BP group were placed on both the shelves and on the cement floor.

Temperatures were recorded and the data were analyzed using the PROC MIXED procedure of the SAS program (SAS Institute, Cary, NC). $\alpha=0.05$ was used to test for significance. 


\section{Results}

\section{Insect Identification}

The live maggots collected from the victim at the scene and at autopsy were reared to adulthood and identified as two blow fly species: C. macellaria and Phormia regina. The preserved larvae collected from the head and chest area of the body were mature third instars of $C$. macellaria and P. regina, whereas larvae collected from the pelvic region of the victim were second and third instars of these same species.

Maggots collected from the LPs group were reared to adulthood and identified as four blow fly species, listed in order of abundance: Calliphora vicina, Cynomyopsis cadaverina, Lucilia coeruleiviridis, and Lucilia sericata. The preserved maggots were premigratory third instars of these same four species.

Maggots collected from the BPs group and reared to adulthood were identified as C. vicina and C. cadaverina. The preserved maggots were premigratory third instars of the same species.

\section{Temperature Data Analysis: Case Study}

Differences between the temperatures inside and outside of the body bag were significant $(F=201.21$; $\mathrm{df}=1276 ; p<0.0001)$. For the time period between the removal of the remains from the scene until autopsy, the average temperature inside the body bag was $14.1^{\circ} \mathrm{C}$, while the average temperature outside of the body bag was $6.3^{\circ} \mathrm{C}$. Because this included the time when the body was being transported to the morgue (a 1-h trip), averages were also calculated for the time when the body was inside of the cooler. The average temperatures for that period were $13.7^{\circ} \mathrm{C}$ inside the body bag and $5.5^{\circ} \mathrm{C}$ outside the body bag.

\section{Temperature Data Analysis: Experimental Study (LP Group)}

The thermocouple attached to LP3 malfunctioned, so the data generated for LP3 were lost. Likewise, the temperature probe recording chest cavity temperature on LP1 malfunctioned and has not been included in this analysis.

When comparing the other three locations, only the underside of the pig and outside of the body bag were not significantly different from each other $(t=0.76$; $\mathrm{df}=588 ; p=0.4476)$. The average temperatures for each site were as follows: underside $5.6^{\circ} \mathrm{C}$, top side $7.7^{\circ} \mathrm{C}$, and outside the body bag $5.8^{\circ} \mathrm{C}$. Because the maggots on this pig were in the body cavity at the time thermocouples were recovered, it is likely that the temperature in this location would have been higher than those of the other temperatures recorded within the body bag, but this cannot be substantiated because of the failed thermocouple. Higher temperatures recorded on top of the pig were likely the result of this body cavity mass, and the temperatures recorded on top of the pig were sufficient to maintain larval development of the primary species that colonized the remains, C. vicina and C. cadaverina $(8,20)$.

Statistical analysis of LP2 showed that each of the four recorded temperatures differed significantly $(p<0.0001)$ when compared with each other, with the exception of maggot mass versus on top of the pig, which were not significantly different $(t=1.35 ; \mathrm{df}=980 ; p=0.1774)$. The chest cavity averaged $9.0^{\circ} \mathrm{C}$, the underside of the pig averaged $7.3^{\circ} \mathrm{C}$, the top side $8.8^{\circ} \mathrm{C}$, and the temperature outside of the body bag averaged $5.0^{\circ} \mathrm{C}$. Each of the sites within the body bag maintained temperatures sufficient for larval development for both $C$. vicina and $C$. cadaverina $(8,20)$.
Each of the four locations in which temperatures were recorded on LP4 was significantly different $(p<0.0001)$ from each other. The chest cavity (site of the original maggot mass) averaged $7.3^{\circ} \mathrm{C}$, the underside of the pig averaged $22.3^{\circ} \mathrm{C}$, the top $6.5^{\circ} \mathrm{C}$, and the outside of the body bag averaged $5.6^{\circ} \mathrm{C}$. This replicate showed the greatest average difference between any single internal temperature and the exterior temperature, $16.7^{\circ} \mathrm{C}$. At the time the pigs were transported to the morgue cooler, the maggots formed a continuous mass between the inside of the body cavity and the underside of the pig. When the thermocouples were recovered and the pigs removed from the morgue cooler, the maggots were aggregated under the pig, and had apparently been able to maintain a fairly constant temperature at that site through the duration of the experiment. This temperature was close to the optimal temperature for larval development for each of the four species of blow flies collected from this pig. Greater tissue loss was noted for LP4 than the other LP replicates.

\section{Temperature Data Analysis: Experimental Study (BP Group)}

BP1 showed significant differences between each of the four locations where temperatures were recorded $(p<0.0001)$. The average temperatures for each location were as follows: mouth $8.4^{\circ} \mathrm{C}$, underside $7.1^{\circ} \mathrm{C}$, top $6.3^{\circ} \mathrm{C}$, and outside of the body bag $5.6^{\circ} \mathrm{C}$. The underside temperature was the most consistent of the four locations, because this pig was placed on the cement floor of the morgue cooler. This minimized the effects of the cooling system operation that caused temperature fluctuations. Each of the interior temperatures recorded on BP1 was above the developmental threshold of $C$. vicina and $C$. cadaverina, so maggot activity would have continued during storage $(8,20)$.

BP2's temperature data revealed significant differences between each of the four temperature recording locations $(p<$ 0.0001). The mouth's average temperature was $8.5^{\circ} \mathrm{C}$, the underside $6.7^{\circ} \mathrm{C}$, the top $5.6^{\circ} \mathrm{C}$, and the outside averaged $5.0^{\circ} \mathrm{C}$. This pig was also placed on the cement floor of the morgue cooler, and showed underside temperatures similar to BP1. Temperatures recorded in the mouth and underside of $\mathrm{BP} 2$ would have been above the developmental threshold temperature of $C$. vicina and C. cadaverina (8), and all of the internal temperatures were above the developmental minimum for $C$. vicina as reported by Marchenko (20).

Comparisons of the temperature data of BP3 showed significant differences between each of the four temperature-recording locations $(p<0.0001)$, despite the similarities between each site's average temperatures (mouth $6.4^{\circ} \mathrm{C}$, underside $5.7^{\circ} \mathrm{C}$, top $5.5^{\circ} \mathrm{C}$, and outside $5.0^{\circ} \mathrm{C}$ ). The average temperature within the pig's mouth was sufficient to support larval development of both $C$. vicina and C. cadaverina (8), and the other internal temperatures were above the developmental threshold of C. vicina (20).

The difference between the temperatures recorded on the top of BP4 and the temperatures outside of the body bag were not significantly different $(t=0.81 ; \mathrm{df}=1096 ; p=0.4194)$, but comparisons among the other temperatures were significantly different $(p<0.0001)$. The average temperatures recorded on BP4 were as follows: mouth $7.6^{\circ} \mathrm{C}$, underside $5.9^{\circ} \mathrm{C}$, top $4.9^{\circ} \mathrm{C}$, and outside $5.0^{\circ} \mathrm{C}$. The average temperature within the pig's mouth was sufficient to support larval development of both C. vicina and C. $\mathrm{ca}$ daverina (8), and the other internal temperatures were above the developmental threshold of C. vicina (20).

\section{Temperature Data Analysis: Trends Across Experiments}

Although the veterinary cooler temperature was set at $4^{\circ} \mathrm{C}$, the actual cooler temperature fluctuated over $5^{\circ} \mathrm{C}$ in both LP 
and BP experiments. Overall, the LP group showed an average chest cavity temperature of $8.2^{\circ} \mathrm{C}$ (SE 0.151$)$, an average underside temperature of $11.7^{\circ} \mathrm{C}$ (SE 0.318), an average top temperature of $7.7^{\circ} \mathrm{C}$ (SE 0.103), and an average outside (cooler) temperature of $5.5^{\circ} \mathrm{C}$ (SE 0.071). Overall, the BP group showed an average mouth temperature of $7.7^{\circ} \mathrm{C}$ (SE 0.035), an average underside temperature of $6.3^{\circ} \mathrm{C}$ (SE 0.025), an average top temperature of $5.6^{\circ} \mathrm{C}$ (SE 0.036), and an average outside (cooler) temperature of $5.1^{\circ} \mathrm{C}(\mathrm{SE} 0.037)$.

\section{Temperature Data Analysis: Fluctuation of Cooler Temperatures}

Temperatures within the experimental cooler proved to be highly variable, fluctuating as much as $6^{\circ} \mathrm{C}$ in a 10 -h time period. Normal fluctuations caused by cooling unit compressors switching on and off were visible, but longer periods of higher temperatures were apparent as well. Because this cooler was located at a busy necropsy laboratory, workers frequently enter and exit the cooler through the work day, causing the temperatures to fluctuate. Additionally, this cooler had a second door that opened to a loading-dock area, and warm fall temperatures would have contributed to rising cooler temperatures when this external door was opened.

Temperatures in the case study cooler did not fluctuate excessively. This is most likely because the body was placed in the cooler on a Saturday evening, and was removed the following Monday morning. In this instance, it is unlikely that anyone opened the morgue door during storage. Because temperatures inside the body bag reflected increases and decreases in ambient cooler temperatures, morgue personnel entering and exiting a cooler could have an effect on the temperatures experienced by the insects on the body.

\section{Tissue Loss and Insect Development: Case and Pig Studies}

Because reliable methods for aging maggots within a stage are not available, indirect measures of insect activity are necessary to confirm continued insect development at morgue temperatures. The easiest and most obvious such indicator is tissue loss associated with maggot feeding.

In the case study, besides direct measurement of temperature inside and outside the body bag, examination of the body at the scene and subsequently at autopsy confirmed that substantial insect development occurred during morgue storage and in a pattern consistent with temperature observations. At the scene, tissue loss from maggot infestations on the back of the victim was limited to sites where stab wounds occurred. At autopsy (c. $40 \mathrm{~h}$ later), maggots had moved to the bottom of the body bag and caused sufficient tissues loss such that vertebrae were exposed. Consequently, both temperature measurements and direct observation of tissue loss demonstrated that maggot development continued in morgue storage.

In both LP and BP studies, patterns and degrees of tissue loss were consistent with temperature observations relative to maggot movement and development. Tissue loss was always associated with areas of highest temperatures and greatest maggot aggregations.

\section{Discussion}

Case Study

The temperature experienced by maggots feeding inside of a body bag averaged $c .8^{\circ} \mathrm{C}$ above the storage cooler's temperature during the course of storage. However, the temperature inside the body bag did not immediately begin declining, but instead experienced a slight increase when the body first entered the cooler. This initial increase in temperature was likely the result of maggots aggregating to a single location within the body bag to facilitate heat generation. As the cold temperatures drew heat from the body bag, the internal temperatures showed a slow, steady decline over a period of about $28 \mathrm{~h}$, after which point the temperature remained at $c .10^{\circ} \mathrm{C}$, which is $c .6^{\circ} \mathrm{C}$ above the ambient temperature of the cooler.

It should be noted that the body in this case was stored in the morgue's cooler for $c .38 .5 \mathrm{~h}$, but the minimum developmental temperature for the species involved, $10^{\circ} \mathrm{C}(8)$, was not recorded inside of the body bag until $28 \mathrm{~h}$ after refrigeration and never went significantly below that temperature. At the time of autopsy, the maggots were aggregated and feeding under the victim's torso. Indeed, the body showed extensive tissue loss from maggot feeding between removal from the scene and autopsy. At autopsy, a maggot mass temperature of $15^{\circ} \mathrm{C}$ was recorded, which was well above the developmental threshold temperature and above the temperature being recorded by the thermocouple inside of the body bag for that same time period. Because the thermocouple was placed on top of the victim's abdominal area, the temperatures recorded at this site were lower than those actually experienced by the insects elsewhere in the body bag.

\section{Experimental Study}

The results of the LP and BP studies confirm observations from the human case study. Maggots clearly do continue development under morgue temperatures, and the actual temperature experienced varies with location on the body. The exact difference between maggot and cooler temperatures depends on the size of the body, the size of the maggot mass, the temperature of the cooler, and how long the body has been in the cooler. In the human case, maggots arrived at a constant temperature in the morgue after $28 \mathrm{~h}$; in the pig experiments constant temperatures occurred after about $24 \mathrm{~h}$ for LPs and $12 \mathrm{~h}$ for BPs. Because these adjustment periods are influenced by a number of environmental factors, it is difficult to ascribe a definitive value to the length of time for any given maggot mass to stabilize thermally. Therefore, it is our opinion that using $24 \mathrm{~h}$ as the adjustment period for thermal stabilization is an acceptable compromise and will provide a more accurate estimate of the actual temperatures experienced by the maggots than assuming that the maggots experienced either the temperature recorded at autopsy for the duration of storage, or worse yet, that the maggots did not develop at all during morgue storage.

\section{Potential for Evidence Loss During Morgue Storage}

The case study and both pig experiments demonstrate that substantial tissue loss is possible from feeding maggots in morgue storage. The degree of loss is variable, but clearly depends on the numbers of maggots initially on the body and on the duration of storage. That almost all muscle tissue in a localized area was removed by maggots in $<2$ days of morgue storage is a sobering observation. When a victim has surface marks or shallow wounds, it is entirely possible that evidence of these could be destroyed by maggot feeding before autopsy. Given that crime scene photographs might not show the underside of a victim, it is possible that evidence could be destroyed by maggots without its presence ever having been noted. 
Finally, the patterns that we observed indicate that as long as temperatures are sufficient for maggot development (above minimum developmental thresholds), movement of the body and changes in ambient temperature do not seem to retard or alter maggot feeding. In contrast, removal of maggots from a body onto an alternative substrate (such as beef liver) does substantially retard development. For example, in the case study presented here, we noted a developmental delay in excess of 60 accumulated degree-days in moving maggots onto the liver. Thus, it appears that maggot feeding is retarded by removal from a substrate even when the temperatures are relatively constant, whereas maggot feeding does not seem to be retarded if maggots are maintained within the substrate, as long as in situ temperatures are above developmental minima.

\section{Estimating PMI after Morgue Storage}

Maggot mass temperatures should be recorded whenever maggots are collected from a body, and this holds true when the collection takes place at autopsy (2). Because maggot mass temperatures show a steady decline during morgue storage, this recorded temperature will be the lowest temperature that the maggots could have experienced during storage. Thus, the actual PMI would be shorter than one estimated on these data, and this should be accounted for when determining the width of the estimate. When these data are not available, the forensic entomologist must estimate the temperatures experienced by the insects during morgue storage.

By calculating the accumulated degree-hours (ADH) experienced by the maggots in the body bag before autopsy, estimates can be made of what degree of error would have been made if the assumption was made that no insect development took place during the time before autopsy. In this case study, based on an average temperature of $14.1^{\circ} \mathrm{C}$ inside the body bag during the $38.5 \mathrm{~h}$ between removal from the scene and autopsy, the maggots would have accumulated $157.1 \mathrm{ADH}_{10 \mathrm{C}}$ before autopsy. In this particular case, $157.1 \mathrm{ADH}_{10 \mathrm{C}}$ translates to an 18 -h overestimate of the actual time of death, which is $c$. an $8.6 \%$ error. Had the body been brought to the morgue on a Friday night, rather than Saturday, and held until Monday for autopsy, the error rate would increase to $c .12 .8 \%$. Conducting the autopsy after overnight storage $(12 \mathrm{~h})$ would have reduced this error rate to $c .2 \%$.

By using the data generated from the porcine replicates, potential error rates of PMI estimates can be assigned for the experimental cadavers. Estimating a PMI based on the maggots obtained following post-mortem refrigeration of the LPs (using a base temperature of $6^{\circ} \mathrm{C}$ for C. vicina (8) and an average temperature of $8.2^{\circ} \mathrm{C}$ for $51 \mathrm{~h}$ ), $111.2 \mathrm{ADH}_{6 \mathrm{C}}$ have accumulated that otherwise would not have been accounted for. Based on weather records at the study site for the time period, this would equate to a 20 -h overestimate of the time of placement, or c. a $6 \%$ error. The same calculations can be applied to the BP maggots: an average temperature of $7.7^{\circ} \mathrm{C}$ for $44.5 \mathrm{~h}, 75 \mathrm{ADH}_{6 \mathrm{C}}$ accumulate. This translates to an 8-h overestimation of time of placement, or c. a $2 \%$ error.

Because of the differences observed between the three groups of replicates, it is difficult to establish a definitive correction factor for calculating the temperature experienced by maggots during morgue storage. The porcine replicates were considerably smaller and had similarly smaller maggot masses than the human victim in the case study. This may have translated to the lower temperatures recorded in their body bags. Similarly, there was likely a species interaction relative to maggot mass temperatures, as the porcine cadavers were infested with cool- weather blow flies (subfamily Calliphorinae) and the human cadaver was infested with warm-weather blow flies (subfamily Chrysomyinae).

From case and experimental data, if the assumption is made that no insect development takes place during preautopsy refrigeration, potential error rates in PMI estimation of 8.6-12.8\% occur. Forensic entomologists must consider this continuing development during the course of an investigation involving samples collected at autopsy. Our findings emphasize the importance of collecting insect material from the body while it is still at the scene and of conducting autopsies on maggot-infested remains as soon as possible. When this is not possible, measurements of maggot mass temperatures at autopsy are important, and in the absence of these data, greater variation in PMI estimates from insect development must be assumed.

\section{Acknowledgments}

We thank Dr. Doug Rogers and Chris Riggert for their help in procuring pigs and for the use of the Veterinary Diagnostic Center's cooler, Matt Anderson at the UNL ARDC Swine Unit for additional pig procurement, and Dr. Phillip Scholl for reviewing a previous version of this manuscript. This research was supported in part by the University of Nebraska Agriculture Experiment Station Project NEB-17-080. This is paper number 15110 of the Journal Series of the University of Nebraska Agricultural Research Division.

\section{References}

1. Spitz WU, editor. Medicolegal investigation of death: guidelines for the application of pathology to crime investigation. 3rd ed. Springfield: Charles C. Thomas, 1993.

2. Haskell NH. Entomological collection techniques at autopsy and for specific environments. In: Catts EP, Haskell NH, editors. Entomology and death: a procedural guide. Clemson: Joyce's Print Shop, 1990:98-110.

3. Haskell NH, Hall RD, Cervenka VJ, Clark MA. On the body: insects' life stage presence and their postmortem artifacts. In: Haglund WD, Sorg MH, editors. Forensic taphonomy: the postmortem fate of human remains. Boca Raton: CRC Press LLC, 1997:415-48.

4. Haskell NH, Lord WD, Byrd JH. Collection of entomological evidence during death investigations. In: Byrd JH, Castner JL, editors. Forensic entomology: the utility of arthropods in legal investigations. Boca Raton: CRC Press LLC, 2001:81-120.

5. Byrd JH, Castner JL. Insects of forensic importance. In: Byrd $\mathrm{JH}$, Castner JL, editors. Forensic entomology: the utility of arthropods in legal investigations. Boca Raton: CRC Press LLC, 2001:43-79.

6. Girard M. Etudes sur la chaleur libre degage par les animaux invertebres et specialement les insects. Paris: Victor Masson, 1869.

7. Catts EP, Haskell NH, editors. Entomology and death: a procedural guide. Clemson: Joyce's Print Shop, 1990.

8. Higley LG, Haskell NH. Insect development and forensic entomology. In: Byrd JH, Castner JL, editors. Forensic entomology: the utility of arthropods in legal investigations. Boca Raton: CRC Press LLC, 2001:287-302.

9. Greenberg B, Kunich JC. Entomology and the law: flies as forensic indicators. Cambridge: Cambridge University Press, 2002. 
10. Catts EP. Problems in estimating postmortem interval in criminal investigations. J Agric Entomol 1992; 9(4):245-55.

11. Goff ML. A fly for the prosecution. Cambridge: Harvard University Press, 2000.

12. Payne JA. A summer carrion study of the baby pig Sus scrofa Linnaeus. Ecology 1965; 46(5):592-602.

13. Hall RD, Doisy KE. Length of time after death: effect on attraction and oviposition or larviposition of midsummer blow flies (Diptera: Calliphoridae) and flesh flies (Diptera: Sarcophagidae) of medicolegal importance in Missouri. Ann Entomol Soc Am 1993; 85(5):589-93.

14. Institutional Animal Care and Use Committee. University of Nebraska policies and procedures manual for the use of animals. Lincoln: University of Nebraska Press, 2004.

15. Micozzi MS. Experimental study of postmortem change under field conditions: effects of freezing, thawing, and mechanical injury. J Forensic Sci 1986; 31(3):953-61.
16. Grisbaum GA, Tessmer JW, Meek CL. Effects of initial postmortem refrigeration of animal cadavers on necrophilous adult fly activity. Southwest Entomol 1995; 20:165-69.

17. Kirkpatrick RS, Olson JK. Summer succession of necrophagous and other arthropod fauna associated with fresh and frozen pig cadavers at a rural site in central Texas. Tex AEM Univ Undergrad J Sci 2002; 2:17-20.

18. Hall DG. The blowflies of North America. Washington DC: The Thomas Say Foundation, 1948.

19. Hall RD, Townsend LH Jr. The blow flies of Virginia (Diptera: Calliphoridae). Blacksburg (VA): The Insects of Virginia: No 11; 1977. Virginia Polytechnic Institute and State University Research Division Bulletin 123.

20. Marchenko MI. Medicolegal relevance of cadaver entomofauna for the determination of the time of death. Forensic Sci Int 2001; 120:89-109. 